\title{
Histopathological Evaluation of Isolatedprobiotic (Pseudomonasfulva) With Special Reference to Immune Response and Growth Performanceofniletilapia(Oreochromis niloticus)
}

\section{Aly S. M., AbouElatta M.*, Nashwa abdelRazek*, Asmaa Omar El- Ramlawy**}

Dept of Pathology, Fac. Vet. Med., Suez Canal Univ. * Dept of Fish Health, Central Laboratory for AquacultureResearch **Dept of Aquaculture Diseases Control, Fish Farming and Technology Institute

\begin{abstract}
The study was conducted on 190Nile tilapia (Oreochromis niloticus) to evaluate the usefulness of the retrieved field isolate of probiotics (Pseudomonas fulva) by determining the in-vitro inhibitory effect against Aeromonas hydrophila. Ten fish were used to isolate the probiotic strain, 60 fish were used to test the safety of the isolate and 120 fish used in the feeding experiment. The effects onthe growth performance and immune response werealso recorded after one and two months of the feeding experiment. The tested isolate showed an inhibitory effect against motile Aeromonassepticemia. The PCR of the isolated strain was identified as p.fulva12-X which seemed safe to tilapia by the intraperitoneal injection. There was highly significant increase in the survival percent and body weight gain in the P.fulvatreated group. After one andtwo monthsof exposure, thenitroblue tetrazolium, lysozyme and phagocytic activities in the P.fulva treated group was significantly increased. After challenge infection using A.hydrophila, the mortality percentage of P.fulvatreated group was $15 \%$ (with $81.25 \%$ RLP)in comparison with the control group that showed $80 \%$ mortality. The histopathology of the treated groups were fully recorded in comparison with the control group after both treatment period and challenge infection. Weconcluded that, the isolate was useful to control motile Aeromonas septicemia. It enhanced the fish growth performance and immune response.
\end{abstract}




\section{Introduction}

Fish are always susceptible to a wide range of bacterial, fungal, parasitic and viral diseases. Additionally; Poorwater quality, high stocking density, and over feeding enhance the disease susceptibility in aquatic animals, including fish (Banerjeeet al., 2017).

Similar to other fish farming, tilapia culture has also facing economic losses because of diseases. At the same time, microbial disease plays an essential role in the aquaculture industry and causes serious financial losses (Acar et al. 2015). For a long time, the most widespread method for the control of bacterial infections in aquaculture was the administration of antibiotics. On the other hand, random, misuse, and unscientific use of such drugs creates several environmental problems such as emergence of drug-resistant bacteria, destruction of aquatic ecosystem and alteration of gut symbiotic flora and so have been restricted to several countries (Ibrahem, 2015).

An alternative and effective approach to antibiotic administration to livestock is the use of probiotics (Modesto et al. 2009), which recently outlined as a live, dead or element of a microbial cell that once administered via the feed or the rearing water influences the host by increasing disease resistance, feed optimization, growth performance,tolerance response, andhealth standards, that is probably achieved via rising the microbial balance of the hosts otherwise the close surroundings (Martínez Cruz et al. 2012).

As might be expected, most of the effects of probiotics are associated with improved performance and to a lesser extent improved immunity against infections. The use of probiotics in place of growthpromoting antibiotics has also been viewed by many leading animal meat producers as a major differentiation factor in highly sophisticated markets. The effects of probiotics on animal performance can be influenced by the variability in farm practices, species, age, method of application, strains of microorganisms and diet. It is now widely accepted that probiotics can improve animal performance through competitive exclusion with pathogens in the digestive systems, and that animals generally benefit from probiotic micro-organisms isolated from their own digestive tracts (Aly, 2009). The aim of the present study was to isolate probiotic strain from the cultured fish and evaluate its efficiency through 
clinical and histopathological investigations.

\section{Materials and Methods}

\section{1-Fish:}

A total numberof 190 live and apparently healthy Nile tilapia (O. niloticus) of both sexes were collected from Fish Farming and Technology Institute(FFTI) and used in this study. A total of 10 O.niloticus $(60 \pm 5 \mathrm{~g})$ were used to isolate the probiotic while, 60 O.niloticus $(40 \pm 5 \mathrm{~g})$ were used to test the safety and 120 O.niloticus $(30 \pm 10 \mathrm{~g})$ were used in the feeding experiment.Fish were kept fiber glass tanks containing dechlorinated tap water and supplied with continuous air, feces was siphoned daily. Fish fed twice daily with a balanced diet at a rate of $3 \%$ body weight and kept for two weeks under observation for acclimation.

\section{2- Experimental design:}

One hundred and twenty Nile tilapia with an average body weight $(30 \pm 10 \mathrm{~g})$ were divided into 2 equal groups, each of 60 fish. Each group was dividedequally into 3 replicates (20 fish per each). The fish wereacclimated in an in-door fiberglass tanks for 14 days. Each tank was supplied with a well oxygenated tap water. Fish were fed 6 days a week for 60 days. The dead fish were recorded and removed daily. Group (1) the control fed basal diet without bacteria. Group (2) fed basal diet containing P. fulva, at a dose of $1 \times 10^{8} \mathrm{CFU} / \mathrm{g}$. The prepared diet was transferred to plastic bags and stored in a refrigerator $\left(4^{\circ} \mathrm{C}\right)$ and this preparation was repeated every two weeks.

\section{3-Growth parameters:}

The fish of each treatment were counted and weighed before the induction of the feeding experiment (w1) and after one month (w2) and two months of the experiment, the following parameters were taken:

a)Weight gain $=W 2-W 1$

b)Specific growth rate (SGR) $=100(\ln \mathrm{W} 2-\ln \mathrm{W} 1) / \mathrm{T}$; where $\mathrm{W} 1$ and $\mathrm{W} 2$ are the initial and final weight, respectively, and $\mathrm{T}$ is the number of days in the feeding period.

c)Feed conversion rate $(\mathrm{FCR})=$ Feed intake $\quad(\mathrm{g}) /$ Weight gain $(\mathrm{g})$.

\section{4- Immunological parameters:}

- Nitroblue tetrazolium activity (NBT).

- Lysozyme activity.

- Phagocytic activity.

\section{5- Histopathological} examination:

Tissue specimens including the liver, kidney, spleen and intestine from each experimental group of treatments were collected by the end of feeding experiment (2 months) and after induction of the challenge infection. The collected 
specimens were immediately fixed in neutral buffered formalin $10 \%$, then dehydrated in ascending concentration of ethyl alcohol, cleared in two changes of xylene, blocked in paraffin, sectioned at $5 \mu \mathrm{m}$ using rotary microtome. The microscopic tissue slides were stained with routine hematoxylin and eosin stain (H\&E stain) and then covered with cover slips. The Histopathological technique was done according to Drury and Wallington, (1980).

\section{6- Statistical analysis:}

Analysis was performed to the measured growth and immunological parameters of the collected samples using analysis of variance (ANOVA) and Duncan's Multiple Range test (Duncan,1955) (mean at significance level of $\mathrm{P}<0.05$ ). Analysis was performedusing Minitab (18) package.

\section{Results:}

Table (1): Phenotypic characters of the isolated probiotic strain.

\begin{tabular}{|c|c|c|c|}
\hline Test & result & $\begin{array}{c}\text { Reactions/ } \\
\text { Enzyme }\end{array}$ & Result \\
\hline Gram stain & - & URE & - \\
\hline Cellular morphology & Rod shape & VP & - \\
\hline Colony shape & Round Creamy, & Oxidase & + \\
\hline GLU & + & Catalase & + \\
\hline CIT & + & IND & - \\
\hline SAC & - & H $S$ & - \\
\hline MAN & - & GEL & - \\
\hline ARA & - & RHA & - \\
\hline INO & - & TDA & + \\
\hline AMY & - & ODC & - \\
\hline MEL & + & LDC & - \\
\hline ONPG & - & ADH & + \\
\hline
\end{tabular}

I-Isolation of the probiotic isolates: Twelve bacterial isolates wereobtained from theintestinal tract of 10fish (O.niloticus) and subjected to the routine morphochemical identification.

\section{II- Antimicrobial activity assay:}

The 12 isolates were investigated for their inhibitory activity against pathogenic A.hydrophila. Only one isolate showed an inhibitory effect against A.hydrophila. The inhibition zonewas $15 \mathrm{~mm}$.

\section{III-Identification of bacterial} isolates:

\section{a) Biochemical identification:}

The isolate that showed in-vitro antimicrobial activity was identified asP.fulvausing (API20E) strip systemwith code2214044(Table 1).

b) Molecular identification:

The PCR product of the isolated strain was used in gel electrophoresis (Fig.1) and 16S rRNA sequencing and the strain was identified as P.fulva12-X. 
GLU: glucose fermentation, CIT: utilization of citrate, SAC: fermentation of sucrose, MAN: fermentation of mannose, ARA: fermentation of arabinose, INO: fermentation of inositol, AMY: fermentation of amygdalin, MEL: fermentation of melibiose, ONPG: nitrophenyl-b-Dgalactopyranoside, URE: urease, VP: Voges-Proskauer test, IND: Indole Test, $\mathrm{H}_{2} \mathrm{~S}$ : production of hydrogen sulfide, GEL: gelatinase, RHA: fermentation of rhamnose, , TDA : tryptophan deaminase, ODC: ornithine decarboxylase, $L D C$ : lysine decarboxylase, $A D H$ : arginine dihydrolase.

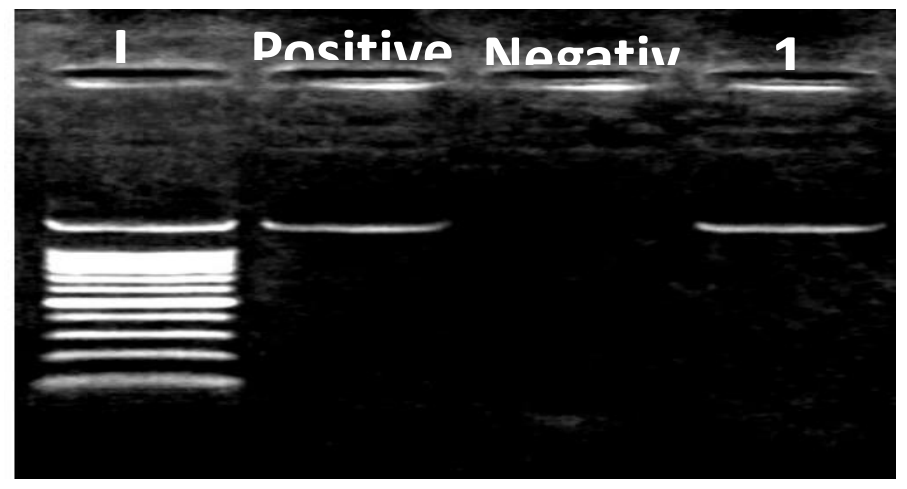

Figure(1): Gel electrophoresis of the PCR product of the isolatedprobiotic strain where, Lane 1 molecular weight ladder; lane 2, a positive control; lane 3 a negative control; lanes 4, the specific DNA product of about 1485 base pairs (bp) amplified from the isolate

\section{IV-Safety of probiotic strains:}

The intra-peritoneal injection of tilapia fish (O.niloticus) with the isolated strain at a dose of $0.3 \mathrm{ml}$ (matching $3 \times 10^{7} \mathrm{CFU} / \mathrm{ml}$ ) was noticed to be non-pathogenic additionally, causing no mortalities among injected fish. Neither mortalities nor disease signs were seen in all fish groups injected with probiotic strain or saline during the period of experiment (15 days) indicating the safety of the isolated bacterial strain.

\section{V-Survival and growth performance: \\ - Survival rate:}

There was highly significant increase in the survival percent of the experimental fish in the treated groupwith probiotic, when compared with the control group during the first and the second month of experimentas seen in Table (2) 
- Body weight gain:

After one month of feeding experiment, the body weight gain of the group treated with probiotic(P.fulva) showed low significant increase compared to the control.

After two months, the body weight gain of the group treated with probiotic (P.fulva) showed a significant increase in comparison with the control group as shown in Table (2)

-Feed conversion rate (FCR) and specific growth rate (SGR): After the first month of feeding trial, the (FCR)of the grouptreated with P.fulva showed a lowsignificant increase value in comparison with the control group. At two months of experiment, the treated group with probiotic showed a significant increase in (FCR) than the control group Table (2).

The specific growth rateof the treated groupwith P.fulvawas significantly higher than that of the control group in the first and the second months, as illustrated in Table (2).

\section{VI- Immunological Parameters:}

VII- Mortality and relative level of protection (RLP) of O.niloticus after bacterial challenge with $A$. hydrophila:

The mortality rate of the challenged fish during the first week after
-Nitroblue tetrazolium test:

After one month of experiment group received $P$. fulva showed a low significant increase inNBTvalues compared to the control.

After two months of feeding experiment, the results of NBT values were significantly higher in the group received probiotic than that in the control (Table 2).

\section{- Lysozyme activity:}

After one andtwo months the lysozyme activity in the treated group was significantly increased incomparison to the untreated control group. (Table 2)

\section{- Phagocytic index:}

After one and two months, group treated with probiotic (P.fulva) showed a significant increase in phagocytic index when compared to the control group (Table2)

\section{-Phagocytic percentage:}

At the first month, the group received probiotic(P.fulva) showed no significant increase in Phagocytic percentage with the control.

At the second month, there was a low significant increase in the Phagocytic percentage in the treated group with probiotic compared to the control (Table2). challenge was illustrated in Table (3).

The mortality percentage of the treated group with probiotic (P.fulva) was $15 \%$ in comparison with the control group that showed $80 \%$ mortality. The RLP in the 
group treated with probiotic was

$81.25 \%$ as seen in Table (3).

\section{VIII- Histopathological findings after 2 months of feeding probiotics:}

\section{- Before induction a challenge infection:}

Group (1): The control group received basal diet:

Normal cellular details and tissue architecture with no marked degenerative changes or inflammatory reactions were seen. Melanomacrophage cells were seen in an inactivated form (Fig.2, $\mathbf{a , b}, \mathbf{c}, \mathbf{d})$.

Group (2): Tilapia received basal diet mixed with $P$. fulva at a dose of $1 \times 10^{8} \mathrm{CFU} / \mathrm{ml}$ for 2 months:

The liver showed vacuolation in the hepatocytes with focal infiltration with leukocytes (Fig.3.a)

The kidney showed mild tubular nephrosis in the form of vacuolar degeneration in the renal epithelium with the presence of melanomacrophage centers and proliferation of hematopoietic tissue (Fig.3.b).

The spleen exhibited moderate infiltration of leukocytes and more activation and proliferation of melanomacrophage centers (Fig.3.c).

In the intestine, the epithelial lining showed mucinous degeneration and focal epithelial desquamation. Mononuclear cells infiltration together with eosinophilic granular cells was seen in the lamina propria and submucosa (Fig.3.d).

Table (2): Measured growth and immunological parameters of the experimental groups after one and two months of feeding experiment

\begin{tabular}{|c|c|c|c|c|}
\hline \multirow{2}{*}{ Parameter } & \multicolumn{2}{|c|}{ Control } & \multicolumn{2}{|c|}{ Strain 1P. fulva } \\
\hline & 1st Month & 2nd Month & 1st Month & 2nd Month \\
\hline Survival \% & $93.75 \pm 1.98^{b}$ & $93.84 \pm 0.10^{b}$ & $98.04 \pm 1.08 \mathrm{a}$ & $95.80 \pm 1.15$ a \\
\hline Body weight gain (g) & $4.93 \pm 0.07 \mathrm{~b}$ & $13.50 \pm 0.68$ b & $7.25 \pm 0.43$ ab & $17.20 \pm 0.48^{a}$ \\
\hline FCR & $0.71 \pm 0.01^{b}$ & $1.25 \pm 0.21^{b}$ & $1.03 \pm 0.1^{a b}$ & $2.07 \pm 0.02^{\mathrm{a}}$ \\
\hline SGR & $0.12 \pm 0.00^{b}$ & $0.25 \pm 0.01^{b}$ & $0.25 \pm 0.00^{\mathrm{a}}$ & $0.41 \pm 0.01^{\mathrm{a}}$ \\
\hline NBT $\mathrm{mg} / \mathrm{ml}$ & $0.07 \pm 0.01^{b}$ & $0.09 \pm 0.01^{b}$ & $0.15 \pm 0.01$ ab & $0.16 \pm 0.01^{\mathrm{a}}$ \\
\hline Lysozyme activity Unit/ml & $0.61 \pm 0.05^{b}$ & $1.02 \pm 0.03^{b}$ & $1.72 \pm 0.02^{a}$ & $2.08 \pm 0.12^{a}$ \\
\hline Phagocytic index & $1.00 \pm 0.03^{b}$ & $1.30 \pm 0.03^{b}$ & $1.60 \pm 0.02^{a}$ & $1.77 \pm 0.04^{\mathrm{a}}$ \\
\hline Phagocytic \% & $21.90 \pm 0.01^{b}$ & $22.20 \pm 0.01^{b}$ & $29.10 \pm 0.03^{a b}$ & $30.65 \pm 0.02^{a}$ \\
\hline
\end{tabular}


Table (3): Mortality percentage and RLP of O.niloticus treated with probiotic and experimentally infected with A. hydrophila.

\begin{tabular}{|c|c|c|c|c|c|c|c|c|c|c|c|c|c|}
\hline \multirow{2}{*}{$\begin{array}{l}\frac{9}{3} \\
\stackrel{3}{6}\end{array}$} & \multirow{2}{*}{ Treatment } & \multirow{2}{*}{$\begin{array}{l}\text { Fish } \\
\text { No. }\end{array}$} & \multirow[t]{2}{*}{$\begin{array}{c}\text { Challenge } \\
\text { A.hydrophila }\end{array}$} & \multicolumn{7}{|c|}{$\begin{array}{l}\text { Dead fish during } 7 \text { days } \\
\text { Post challenge }\end{array}$} & \multirow{2}{*}{$\begin{array}{l}\text { Total } \\
\text { No. of } \\
\text { dead } \\
\text { fish. }\end{array}$} & \multirow{2}{*}{$\begin{array}{c}\text { Mortality } \\
\%\end{array}$} & \multirow{2}{*}{$\underset{\%}{\text { RLP }}$} \\
\hline & & & & 1 & 2 & 3 & 4 & 5 & 6 & 7 & & & \\
\hline 1 & Control & 20 & $\begin{array}{c}1 \mathrm{ml} \text { of } \\
3 \times 10^{8} \\
\text { CFU/ml }\end{array}$ & 4 & 2 & 2 & 3 & 3 & 2 & - & 16 & 80 & O \\
\hline 2 & P.fulva & 20 & $\begin{array}{c}1 \mathrm{ml} \text { of } \\
3 \times 10^{8} \\
\text { CFU/ml }\end{array}$ & 1 & 1 & 1 & - & - & - & - & 3 & 15 & 81.25 \\
\hline
\end{tabular}

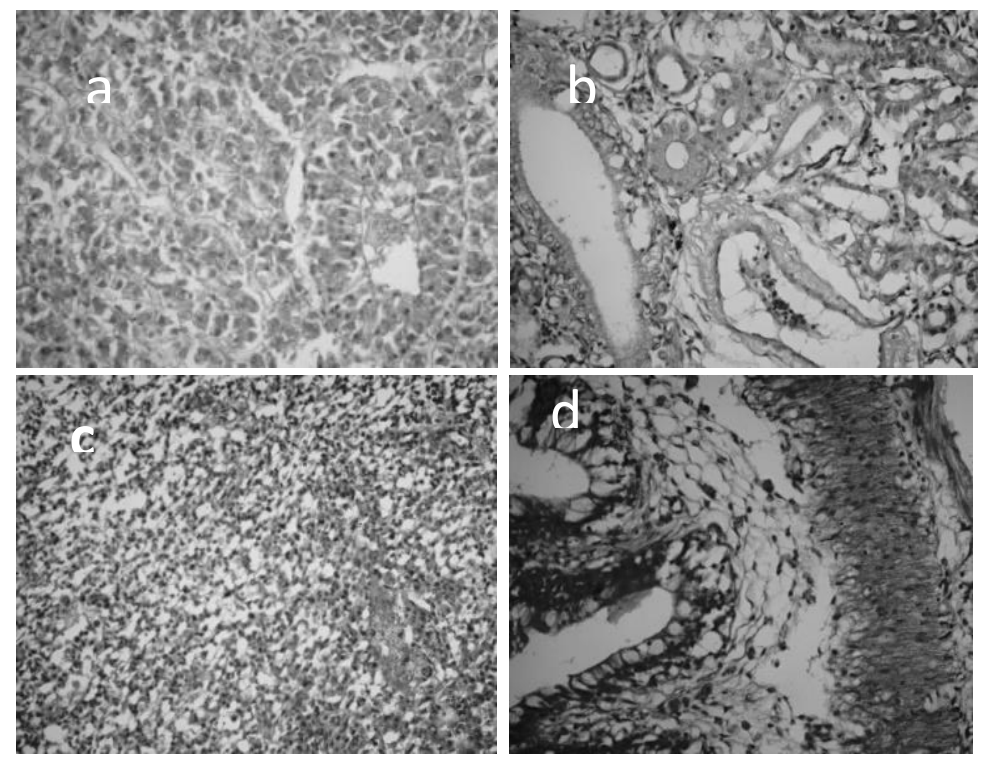

Figure (2):Histopathological findings of group (1) the control Tilapia received basal diet for 2 months showing normal cellular details and tissue architecture ;(a) hepatopancreas, (b)hematopoietic of renal tissue, (c) splenic parenchyma, (d) intestine ( H\&E stain, X400). 

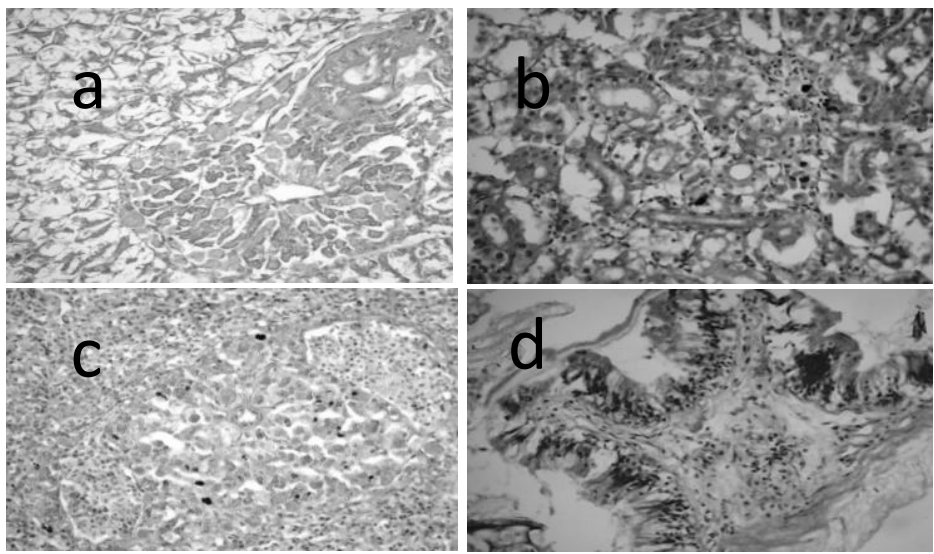

Figure (3):Histopathological findings of group (3) Tilapiatreated with strain $2 P$. fulva with dose $1 \times 10^{8} \mathrm{CFU} / \mathrm{ml}$ for 2 monthsshowing ;(a) hepatic cellular vacuolation , and focal proliferation of MMC, (b) renal epithelial vacuolar degeneration of MMC,hematopoietic tissue proliferation (c) splenic congestion with moderate proliferation of leukocytes and activation of melanomacrophage centers, (d) intestinal mucinous degeneration in the epithelial lining with Mononuclear cells infiltration together with eosinophilic granular cells in the lamina propria and submucosa(H\&E stain, X400
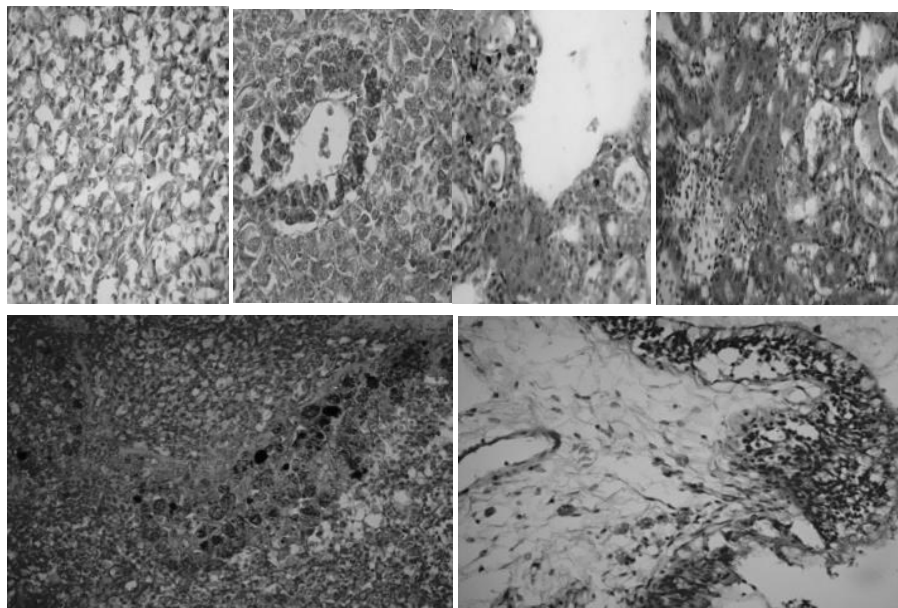

Figure (4): Histopathological findings of group (1) the control Tilapiaafter challenged with $\boldsymbol{A}$. hydrophila. showing, a. the hepatocytes showing massive vacuolar degeneration and coagulative necrosis and the pancreatic acinar cells and MMCs showed marked necrosis, b. the renal 
tubules showing coagulative necrosis, focal infiltration of mononuclear cells. Atrophy in MMCs \& focal depletion in hematopoietic tissue. C, spleen showing depletion in the lymphoid follicles of spleen and inactivation as well as atrophy in MMCs, d. Intestine mucinous degeneration ,focal coagulative necrosis in the epithelial lining, epithelial sloughing or infiltration with mononuclear leukocytes together with edema in the lamina propria ,mononuclear as well as eosinophilic granular cells infiltration (H\&E stain,X400).

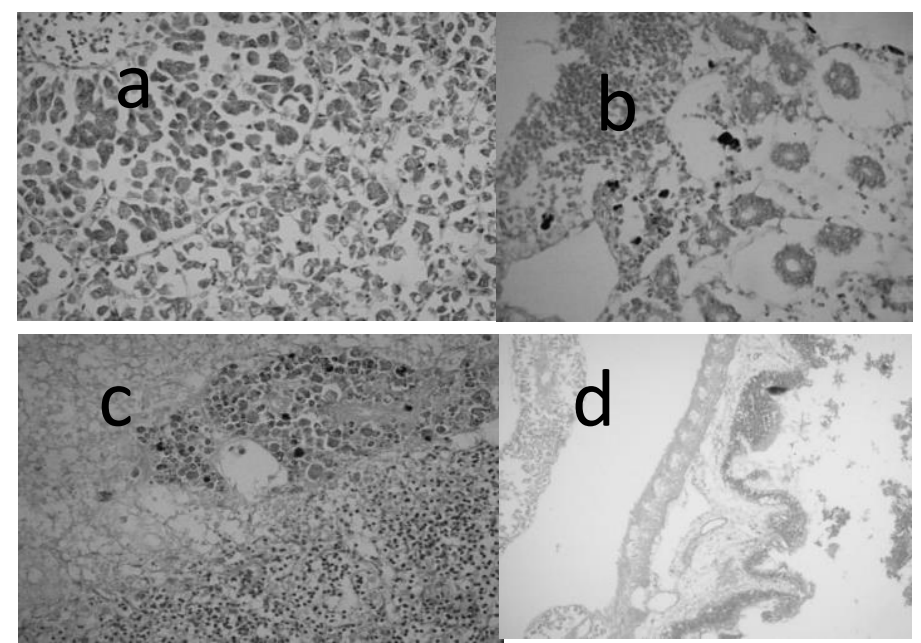

Figure (5):Histopathological findings of group (2)Tilapia received $\boldsymbol{P}$. fulva and challenged with A. hydrophila where; a. The hepatic tissue showing marked edema, congestion, vacuolar degeneration , and marked proliferation of inactivated MMCs .b. Kidney showing atrophy of renal tubules with interstitial edema ,focal depletion \&hyperplasia in hematopoietic tissue with presence of MMCs. c. Spleen showing alternative focal depletion \&hyperplasia of splenic hematopoietic tissue and multiple proliferation of MMCs. d. intestine showing mucinous degeneration in the epithelial lining of intestine with edema and eosinophilic granular cells infiltration in the lamina propria and submucosa.

\section{a-After induction of challenge infection:}

Group (1): The control group challenged $\mathbf{I} / \mathbf{P}$ A.hydrophilaat

\section{of $3 \times 10^{8} \mathrm{CFU} / \mathrm{ml}$ after 2 months of feeding experiment:}

The hepatocytes and pancreatic with acinar cells showed marked a dose coagulative necrosis and atrophy in MMCs. Massive vacuolar 
degeneration in the liver tissue was evident (Fig.4.a).

The kidney revealed coagulative necrosis in the epithelium of renal tubules with focal infiltration of mononuclear cells.Atrophy and degeneration in MMCs was seen with focal depletion in hematopoietic tissue(Fig.4.b).

The spleen showed depletion in the lymphoid follicles and inactivation as well as atrophy in MMCs (Fig.4.c).

The intestine exhibited advanced mucinous degeneration with focal coagulative necrosis in the epithelial lining which showed either focal epithelial sloughing or infiltration with mononuclear leukocytes. The lamina propria revealed edema, congestion and mononuclear as well as eosinophilic granular cells infiltration(Fig.4.d).

The Intestine showed epithelial mucinous degeneration with focal epithelial sloughing. The lamina propria\& submucosa revealed marked edema and infiltration with eosinophilic granular cells(Fig.4.d).

Group(2): Tilapia fishfed diet with probioticP. fulvafor 2 months and challenged $I / P$ with $\begin{aligned} & \text { A.hydrophilaat a dose } \\ & \text { of } 3 \times 10^{8} \mathrm{CFU} / \mathrm{ml} \text { : }\end{aligned}$
a

The hepatopancreas exhibited marked edema, congestion and vacuolar degeneration together with marked proliferation of inactivated MMCs (Fig.5.a).

The kidney revealed atrophy in the majority of renal tubules with marked interstitial edema. Alternativefocal depletion andhyperplasia in hematopoietic tissue and MMCs was evident (Fig.5.b).

The spleen showed focal depletion and hyperplasia of hematopoietic tissue with multiple proliferations of MMCs (Fig.5.c).

The intestine suffered mucinous degeneration in the epithelial lining along with edema and eosinophilic granular cells infiltration in the lamina propria and submucosa (Fig.5.d)

\section{Discussion}

In the present study, samples from the intestine were cultured on TSB and incubated at $30^{\circ} \mathrm{C}$ for 24-48h. The isolated strains were purified through sub culturing onTSA. Twelve bacterial isolates were obtained from the intestinal tract of 10 tilapia fish(O.niloticus), only one isolates showed an inhibitory effect against the pathogenic $A$. hydrophila. The isolate was identified as P.fulvausingAPI20E andfurther molecular diagnostic tools.Similar findings were reported by Sebastião et al.,(2015) who isolated both P.fulva (20\%) from the skin and the kidneyand P. putida (27\%) 
from the spleen of tilapia fish.Those two strains werethe predominant Pseudomonas species observed. These results were also agreed with Spanggaardet al., (2001) who recognized commensal microflora fromthe intestine of rainbow trout (O.mykissWalbaum).Nine of the isolated strains were Pseudomonas sp.

In our study, the antimicrobial activity assay was performed by applying agar disc diffusion method. The inhibition zone of $P$. fulva was $15 \mathrm{~mm}$ against pathogenicA.hydrophila. Related results were reported by Aly $\boldsymbol{e t}$ $a l .,(2008 \boldsymbol{b})$ who recorded that, $B$. subtilis and $L$. acidophilus inhibited the growth of $A$. hydrophila in vitro.The intraperitoneal injection of O.niloticuswith isolated strain at a dose of $0.3 \mathrm{ml}$ matching $3 \times 10^{7}$ $\mathrm{CFU} / \mathrm{ml}$ was noticed to be nonpathogenic as well as causing no mortalities during a period of 15 days indicating the safety of the isolated bacterial strain. This result was supported by Eissa and AbouElGheit (2011) who tested the isolated $P$. fluroscensbiovars I, II and III and noticed that they were non-pathogenic and safe to O. niloticus.

The best growth and immunological results were recorded in this study after two months of feeding experiment indicated the effective role of the isolated $P$. fulvain Tilapia cultures. These results were agreed withAly et al.,(2008 b) whoconcluded that, $B$. subtilis and $L$. acidophilus significantly increase the nitroblue-tetrazolium (NBT) assay, neutrophil adherence, and lysozyme activity and showed a significant increase in the serum bactericidal activityin $O$. niloticus after induction of the feeding trial. Conversely Hai, et al., ( 2009)studied the effects of two selected probiotics $(P$. aeruginosa and $P$. synxantha) on the SGR, rate of survival and immune parameters of western king prawns juveniles (Penaeuslatisulcatus) for 84 days. $P$. synxantha and $P$. aeruginosa wereeithersupplemented in the formulated feed at a concentration of $10^{5} \mathrm{CFU} / \mathrm{mL}$ for each probiotic or applied into the rearing medium. The results showed that probiotic treatments resulted in no significant difference in the SGR and survival of the prawns, but meaningfully decreased the food conversion ratios compared with the control with no probiotics treatment.

The histopathological examination of the different specimens collected from the group received probiotic revealed activation of Melanomacrophage cellsand infiltration with lymphocytes in the hematopoietic organs 
including liver, spleen and anterior kidney which indicate the role played by probiotics in immune cellular response.

\section{Conclusion}

The isolated probiotic strain $(P$. fulva) showed an obvious inhibitory effect against $A$. hydrophila both in-vitro and invivo. It is recommended to use it in Tilapia farms to prevent and control A.hydrophila infections and the best growth and immunological results showed to be after two months of feeding experiment at a dose of $1 \times 10^{8} \mathrm{cfu} / \mathrm{g}$.

However, further studies are recommended to explore new probiotics andconfirm as well as correlate between their efficiency against the different fish pathogens.

\section{References}

Acar, Ümit, Osman Sabri Kesbiç, SevdanYılmaz, NejdetGültepe, and Ali Türker (2015): "Evaluation of the Effects of Essential Oil Extracted from Sweet Orange Peel (Citrus Sinensis) on Growth Rate of Tilapia (Oreochromis mossambicus) and Possible Disease Resistance against Streptococcus iniae." Aquaculture 437: 282-286.

Aly, Salah Mesalhy (2009): "Probiotics and Aquaculture."
CAB Reviews: Perspectives in Agriculture, Veterinary Science, Nutrition and Natural Resources 4 (074): 1-16.

Aly,Salah Mesalhy, Yousef
Abdel-Galil Ahmed, Ahlam
Abdel-Aziz Ghareeb, and
MoahmedFathi r Mohamed
(2008b): "Studies on Bacillus
Subtilis and Lactobacillus
acidophilus, as Potential Probiotics, on the Immune Response and Resistance of Tilapia Nilotica (Oreochromis niloticus) to Challenge Infections." Fish \& Shellfish Immunology 25 (1): 128136.

Banerjee, Goutam, Ankita Nandi, and Arun Kumar Ray (2017): "Assessment of Hemolytic Activity, Enzyme Production and Bacteriocin Characterization of Bacillus subtilis LR1 Isolated from the Gastrointestinal Tract of Fish." Archives of Microbiology 199 (1): 115-124.

Drury RAB, Wallington E.A. (1980): Preparation and fixation of tissues. In: Drury RAB, Wallington EA, editors. Carleton's Histological Technique. 5. Oxford: Oxford University Press;. pp. 41-54.

Duncan, David B. (1955): "Multiple Range and Multiple F Tests." Biometrics 11 (1): 1-42.

Eissa, Nour, and ElsayedAbouEIGheit (2011): "Efficacy of Pseudomonas Fluorescens as Biological Control Agent against Aeromonas 
hydrophila Infection in Hermosillo, and Hugo C. Oreochromis niloticus." World Ramírez Saad (2012): "Use of Journal of Fish and Marine Probiotics in Aquaculture." Sciences 3 (January): 564-69. ISRN

https://doi.org/10.13140/2.1.3298.5 Microbiology2012.http://downloa 604.

Hai, Ngo Van, Nicky Buller, and Ravi Fotedar (2009): "Effects of Probiotics (Pseudomonas synxantha and Pseudomonas aeruginosa) on the Growth, Survival and Immune Parameters of Juvenile Western King Prawns (Penaeus latisulcatuskishinouye, 1896)." Aquaculture Research 40 (5): 590-602.

Ibrahem, Mai D. (2015): "Evolution of Probiotics in Aquatic World: Potential Effects, the Current Status in Egypt and Recent Prospectives." Journal of Advanced Research 6 (6): 765791.

Martínez Cruz, Patricia, Ana L. Ibáñez, Oscar A. Monroy ds.hindawi.com/journals/isrn.micro biology/2012/916845.pdf.

Sebastião, F. A., L. R. Furlan, D. T. Hashimoto, and F. Pilarski. (2015): "Identification of Bacterial Fish Pathogens in Brazil by Direct Colony PCR and 16S RRNA Gene Sequencing." Advances in Microbiology 5 (06): 409.

Spanggaard, Bettina, Ingrid Huber, Janne Nielsen, Esben B. Sick, Christian B. Pipper, Torben Martinussen, Wilhelmina J. Slierendrecht, and Lone Gram (2001): "The Probiotic Potential against Vibriosis of the Indigenous Microflora of Rainbow Trout." Environmental Microbiology 3 (12): 755-765. 


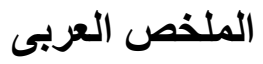

اجريت الدر اسة على 190 سمكة بلطى نيلي لتقييم مدى فاعلية سيدوموناس فولفا المعزولة عن فن فئل

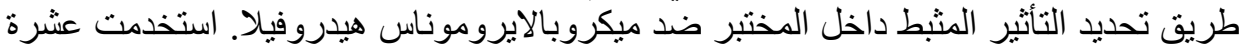

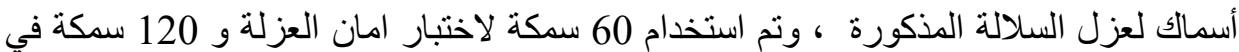

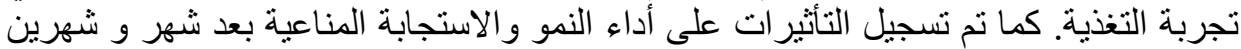

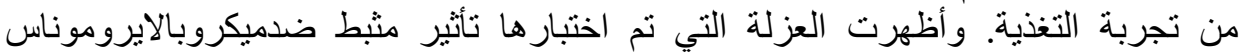

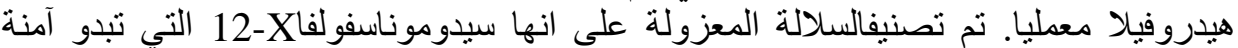

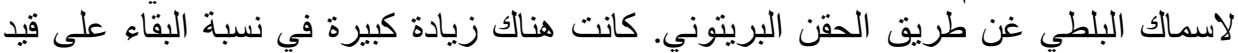

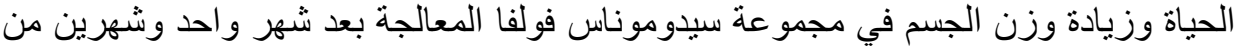

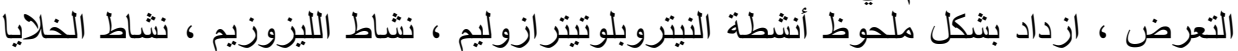

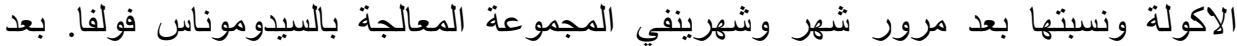

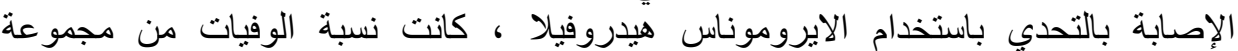

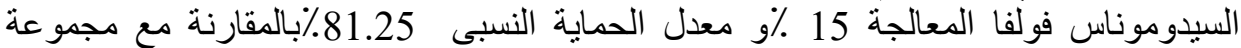

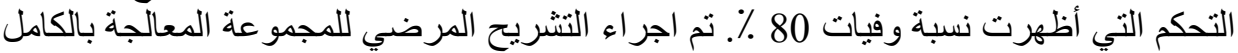

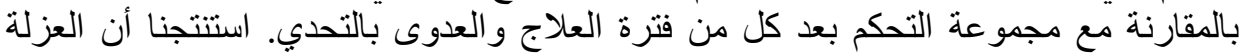

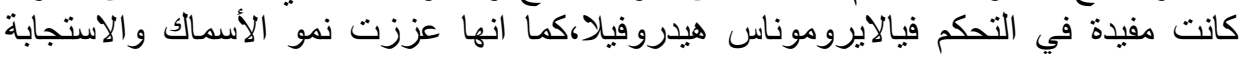

